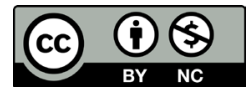

Licenciado sob uma licença Creative Commons

ISSN 2175-6058

DOI: http://dx.doi.org/10.18759/rdgf.v20i3.1798

\title{
CONSTITUCIONALISMO, ESTADO DE DIREITO E A INVISIBILIDADE SOCIAL QUE “TEIMA” EM CONTINUAR
}

CONSTITUTIONALISM, RULE OF LAW AND THE SOCIAL INVISIBILITY THAT "INSISTS" TO CONTINUE

Jose Luis Bolzan de Morais

Nelson Camatta Moreira

\section{RESUMO}

0 presente artigo conecta o Direito Constitucional à Literatura pela via do debate entre as questões apresentadas nas obras de Ralph Ellison e Lima Barreto, que tratam de preconceito, discriminação e invisibilidade social. Com este pano de fundo pretende-se problematizar e se discutir as insuficiências de um modelo de Estado de Direito (Democático). Para tanto, num primeiro momento, aborda-se a obra de Ellison; em seguinda, a de Lima Barreto; para, finalmente, se inserir um debate que apresenta a necessidade do enfrentamento de problemas como a herança escravocrata e o difícil processo de afirmação de um modelo de Estado efetivamente garantidor de direitos fundamentais no Brasil.

Palavras-Chave: Direito e Literatura. Ralph Elison. Lima Barreto. Estado de direito - Invisibilidade social.

\section{ABSTRACT}

This article connects Constitutional Law to Literature through the debate between the issues presented in the works of Ralph Elison and Lima Barreto, 
which deal with prejudice, discrimination and social invisibility. With this background we intend to problematize and discuss the shortcomings of a (Democratic) Rule of Law model. To this end, at first, the work of Elison is approached; then Lima Barreto's; to finally, get to a debate that presents the need to confront problems such as the slave inheritance and the difficult process of consolidating a State model which effectively guarantee fundamental rights in Brazil.

Key-Words: Law and literature. Ralph Elison. Lima Barreto. Rule of law. Social invisibility.

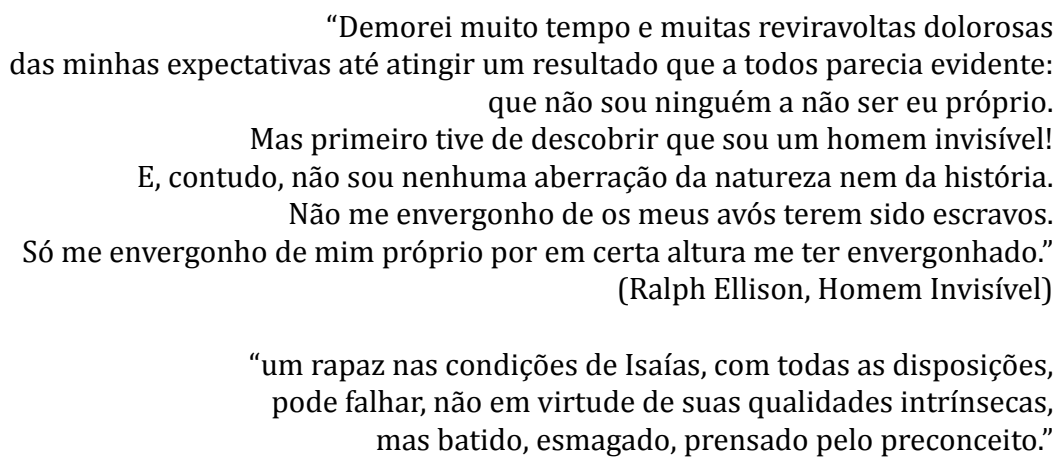

(Lima Barreto)

\section{INTRODUÇÃo}

As conexões entre Direito e literatura nos permitem estabelecer múltiplas possibilidades para a compreensão e elaboração dos fenômenos jurídicos e, aqui, em especial nos dá a oportunidade de retomar um autor que, quando se completam 25 anos de sua morte - agora em 2019 -, se tornou a obra obrigatória da literatura negra americana, como se verá no tópico primeiro deste ensaio.

E, não é à toa a opção aqui feita. Nestes anos difíceis experimentados por uma longa escala de afrontas aos direitos humanos, como tais, ou como direitos fundamentais, para quem os diferencia por estarem ou não explicitados em textos constitucionais positivados, entre outras afrontas à democracia - como experiência político-jurídico moderno -, é preciso reconhecer as dificuldades porque passam o constitucionalismo e o sua formulação como Estado de Direito, como enfrentaremos no terceiro 
tópico, tomando, em paralelo a obra de Lima Barreto - Recordações do Escrivão Isaías Caminha - publicada no início do século passado nestas terras, que servirá de referencial para a construção da segunda parte do texto, permitindo pensar as insuficiências e incoerências desta construção cara à tradição do liberalismo.

Assim, tanto um (Ellisson), a partir da realidade estadonidense, na metade do século XX, quanto outro (Barreto), vivenciando a transição para uma (promessa) de República no início do século XX, no Brasil, denunciam, com a elegância e profundidade literárias, o que há de mais abjeto no convívio social, qual seja: a objetificação (a coisificação) do ser humano e, consequentemente, a humilhação social experimentada por todos aqueles submetidos a tal situação.

Em ambas as histórias literárias, encontram-se, com riqueza, materiais para pesquisas e reflexões sobre a (im)possibilidade de um projeto de Estado de Direito, mais especificamente no choque entre seus ideais de respeito à legalidade, à igualdade e à dignidade humana e a incapacidade das sociedades e dos Estados, no Brasil e nos Estados Unidos, cada qual à sua maneira, de superar as mazelas da "doença histórica" chamada escravidão ou, amplificadamente, da exclusão social baseada em circunstâncias de raça ou cor da pele.

Por isso, o texto faz esta abordagem a partir de duas obras literárias, de dois autores que nunca se conheceram, viveram em lugar e épocas diferentes, mas que parecem dialogar perfeitamente sobre o tema: preconceito e discriminação em relação ao negro em suas respectivas realidades.

E o fazemos assim: num primeiro momento, uma abordagem a obra "Invisible Man", de Ralph Ellison, e a sua visão sobre a desigualdade e a invisibilidade de um personagem que traduz muito das vivências de um rapaz pobre e negro, na sociedade norte-americana, no século XX. Em seguida, apresentamos as experiências de Isaias Caminha, personagem da obra "Recordações do Escrivão Isaias Caminha”, de Lima Barreto, e suas angústias diante de um Estado tendencioso e uma sociedade também excludente, desigual e preconceituosa, no Brasil do fim do século XIX e início do século XX. Por fim, o texto relaciona estas duas obras com uma visão crítica acerca dos ideais de um projeto de Estado de Direito. 


\section{A NATURALIZAÇAO DA DESIGUALDADE NA OBRA "INVISIBLE MAN", DE RALPH ELISSON}

Primeiro romance de um autor desconhecido, provocou intensa polémica aquando da sua publicação, em 1952. Posteriormente foi considerado pela crítica uma obra-prima e reconhecido por muitos como a melhor obra afro-americana de sempre.

Homem Invisível, romance de Ralph Ellison (Oklahoma City, 1914Nova York, 1994), publicado em 1952, é uma obra-prima da literatura norte-americana. Enfocando questões raciais de uma localidade e época determinadas, o romance ainda tem muito de atual e universal para nos ajudar a pensar o projeto inacabado do constitucionalismo como Estado de Direito, pois revela a dor da existência do homem negro num mundo branco, a partir da história de viagem de um jovem negro pelos estados sulistas da América nos primeiros anos do século XX quando, entre experiências frequentemente contraditórias, o protagonista reconhece o mundo dos negros, o mundo dos brancos e o seu próprio mundo, passando a compreender questões fundamentais como a raça, a existência humana e os ideais democráticos.

Para compreendermos o contexto da obra é preciso ter presente, desde logo, que o personagem principal dessa história nunca revela seu nome. Afinal ele é invisível, ou o fizeram acreditar nisso, numa invisibilidade, como uma total falta de importância.

Como negro, de origem pobre, ele não é absolutamente ninguém. Logo no começo de sua jornada, ele ainda não sabe disso, aliás, nem tem consciência da anormalidade que é os negros não serem ninguém diante dos brancos, no sul dos Estados Unidos, não muito tempo depois da escravidão. Para o personagem basta fazer tudo certo, estudar, ser esforçado, mostrar aos brancos e aos negros poderosos que ele é diferente dos outros negros para que tudo aconteça da melhor forma possível.

Em consequência, aceitou ser humilhado por muitos homens brancos para conseguir uma bolsa de estudos na Escola, passando por muitas situações constrangedoras, sempre calmo e de cabeça baixa. $\mathrm{Na}$ escola, passa a ter uma grande admiração pelos negros que conquistaram o poder, e assim como eles, pensa em um dia ter um bom cargo e renegar 
as suas origens. Pensa ele sobre estes: “(...) ele era o exemplo vivo de tudo o que eu almejava ser: influente junto aos homens ricos de todo o país, consultado a respeito de assuntos de interesse da raça, um líder do seu povo, dono não de um, mas de dois Cadillacs, de um bom salário e de uma esposa suave, bonita e de pele mais clara."

Mas, mesmo fazendo tudo como mandavam, ele acaba tendo 'azar', não 'agradando' o suficiente e sendo expulso. Ainda pensando que é o único culpado por sua falta de sorte, vai para o Norte conseguir emprego para poder voltar à Escola. Logo na chegada, fica deslumbrado com a liberdade que os negros têm de andar entre os brancos, de não precisar ficar em pé ou na parte de trás no ônibus, de poder andar encostado a mulheres brancas.

Um dia, no entanto, ele vê um casal sendo despejado, um casal de idosos negros. Ele não pretende envolver-se com a situação, não quer pensar que aquelas pessoas têm a ver com suas raízes. Observando os móveis do casal, que são jogados na rua, ele vê documentos da época da escravidão, pensa no quanto essas pessoas sofreram. A multidão em volta quer fazer uma rebelião e impedir o despejo. Ao contrário, o "invisível" tenta se colocar contra isso, sua razão fala para incentivar a ordem, pois ele foi educado para obedecer e não questionar, mas algo mais forte $o$ impulsiona e ele discursa, levando as pessoas a refletirem sobre como aqueles idosos chegaram aos mais de 80 anos, trabalharam tanto e não têm absolutamente nada, nem ao menos um teto para morar.

Neste momento ele começa a ter um pouco de consciência, que se os negros estavam naquela situação não era por incapacidade ou incompetência, ou qualquer tipo de inferioridade, mas sim porque havia todo um sistema os impedindo de progredir. Por isso, é escolhido para participar de uma organização, fazem-no acreditar que está trabalhando pelos humildes. Faz palestras, atrai multidões para uma causa, é o mais carismático e não entende quando os colegas o barram sob acusações de estar se promovendo com o nome da organização. É afastado do centro das ações e quando volta, está tudo mudado, muitos abandonaram a causa. A organização pra ele, pregava a união entre negros e brancos em nome de um bem maior. 
Enquanto isso, há a presença ameaçadora de Rás, o exortador, uma figura estranha que está sempre a acusar os membros da organização de traidores dos negros e incentivando que negros e brancos não podem estar juntos pela mesma causa.

Nosso protagonista é sacudido pela morte de um dos maiores membros da Confraria, Clifton, assassinado por um policial por vender bonecos na rua. Abandonado pela organização, ele reúne aliados entre os populares para um protesto, mas é duramente censurado pelos líderes. Nesse momento, começa a acordar para a realidade, sabendo que o amigo foi assassinado por ser negro e vendo os líderes da confraria se omitindo e abandonando a população que ele havia conquistado e atraído.

O discurso do irmão Jack e outros continua ecoando com outras palavras em quem prefere afirmar que o racismo não existe ou vai parar de existir quando não se falar mais nele e ignorar suas consequências. Mas nosso Homem Invisível descobre o que ainda hoje é a realidade, ele não pode ser apenas um homem, sendo um homem negro é obrigado a abraçar uma causa, a lutar por uma causa. E que não é sob a liderança de homens brancos que essas causas vão ser defendidas. A Confraria se revela uma armadilha e que, junto com Rás, ele foi usado para atrair uma multidão de negros para iniciar um conflito racial que só resultaria no derramamento do sangue negro.

Rendido e desiludido, ele aceita que sempre foi movido por ilusões, de ir para uma faculdade, de tornar-se alguém importante, destacar-se entre os negros, ser útil a humanidade, tudo isso foi-lhe negado, restando apenas a opção da invisibilidade.

Ele tentou de todas as formas, primeiro obedecendo, depois questionando, em seguida subvertendo, tudo para compreender que continuava sendo um ninguém, incapaz de mudar o seu próprio destino, gerando um conflito com o leitor possivelmente inserido em uma sociedade que prega os valores do esforço individual e da meritocracia. Afinal, nestes termos, nem todos alcancem o lugar que merecem.

Em síntese, o romance Homem Invisível é a história de um jovem negro que leva uma vida secreta em um porão profusamente iluminado por energia elétrica roubada de uma prestadora de serviços públicos. O livro narra suas experiências grotescas e frustrantes. Ao ganhar uma 
bolsa de estudos para uma faculdade exclusivamente para negros, ele é humilhado pelos brancos; ao chegar lá, vê o presidente da escola menosprezar os problemas dos negros americanos. A vida também está corrompida fora da faculdade. Por exemplo, mesmo a religião não serve de consolo: um pregador acaba por se revelar um criminoso. 0 romance acusa a sociedade de falhar em prover seus cidadãos - negros e brancos - com ideais e instituições capazes de realizá-los. 0 romance expressa um tema racial forte porque o "homem invisível" não é invisível por si mesmo, mas porque os outros, cegos pelo preconceito, não conseguem vê-lo pelo que é. Como reflete o personagem:

Sou um homem invisível. Não, não sou um fantasma como os que assombravam Edgar Allan Poe; nem um desses ectoplasmas de filme de Hollywood. Sou um homem de substância, de carne e osso, fibras e líquidos - talvez se possa até dizer que possuo uma mente. Sou invisível, compreendam, simplesmente porque as pessoas se recusam a me ver. Tal como essas cabeças sem corpo que às vezes são exibidas nos mafuás de circo, estou, por assim dizer, cercado de espelhos de vidro duro e deformante. Quem se aproxima de mim vê apenas o que me cerca, a si mesmo, ou os inventos de sua própria imaginação - na verdade, tudo e qualquer coisa, menos eu.

Tudo fica evidente em uma passagem quando o narrador conta um evento em que acidentalmente esbarrou em um homem alto e louro, sendo logo insultado por este - um insulto que faz referência à sua raça. Inconformado, o narrador pede para que ele lhe peça desculpas. Não sendo atendido, agride o branco, que aparece, no dia posterior, como a vítima do acontecido, "segurando o seu colarinho numa das mãos e abrindo o canivete com os dentes, quando me ocorreu que aquele homem, na verdade, não tinha me visto." (ELLISON, 1990, p. 8)

E, tal exemplificação pode muito bem dialogar com a própria tradição literária brasileira quanto enfrenta estes temas, como se tem em Lima Barreto e seu escrivão Isaías Caminha, não só para demonstrar a universalidade deste debate, como também sua atemporalidade, a indicar as insuficiências das fórmulas jurídico-políticas que têm sido construídas junto à tradição do Estado de Direito, como veremos na sequência. 


\section{AS PROMESSAS FRUSTADAS DE UM ESTADO DE DIREITO NA OBRA “RECORDAÇÕES DO ESCRIVÃO ISAIAS CAMINHA"}

Recordações do Escrivão Isaías Caminha foi o primeiro romance de Lima Barreto, publicado sob a forma de folhetim na revista Floreal, da qual ele foi cofundador, e, depois, como livro em 1909, por uma editora portuguesa. (BARBOSA, 2003, p. 181-191)

O livro conta a história de Isaías Caminha, um jovem pobre, mulato, nascido no interior, que deixa a casa dos pais para tentar a vida na capital. Embora contasse com os predicados necessários para ter sucesso em sua empreitada (era um bom moço, inteligente, honesto, com alguma ambição de vencer), Isaías chega ao Rio de Janeiro munido de uma carta de recomendação, que lhe fora outorgada pelo coronel do lugarejo onde vivia, a pedido de seu tio, para que pudesse se apresentar a um deputado na capital e, assim, obter um emprego.

Quer dizer, Lima Barreto já procura destacar aí a ausência daquele sentimento republicano na primeira república brasileira, isto é, daquela virtude representada pela "renúncia às vantagens privadas em favor do bem comum e da coisa pública"(RIBEIRO, 2012), porque, para Isaías, a obtenção de um emprego só seria possível pela intercessão do deputado. Assim, antes mesmo de partir para a capital, apressou-se em fazer uso das relações pessoais do seu tio para obter alguma aproximação com quem, exercendo um cargo público (o deputado), teria condições se, valendo-se das prerrogativas decorrentes da função pública que exercia, arranjar-lhe um emprego.

Isaías via nesse emprego uma condição indispensável para alcançar o sonho de, livrando-se de sua condição de nascimento (pobre e mulato), tornar-se doutor: "a minha situação no Rio estava garantida. Obteria um emprego. Um dia pelos outros iria às aulas, e todo fim de ano, durante seis, faria os exames, ao fim dos quais seria doutor!”.(BARRETO, 2010, p. 75)

Sem o amparo de um padrinho, Isaías sabia que dificilmente alcançaria o seu sonho de se tornar doutor e de alcançar os privilégios daí decorrentes: "Oh, ser formado, de anel no dedo, sobrecasaca e cartola, inflado e grosso (...); andar assim pelas ruas, pelas praças, pelas estradas, 
pelas salas, recebendo cumprimentos: Doutor, como passou? Como está, doutor? Era sobre-humano!..."(BARRET0, 2010, P. 75)

Seu objetivo era se tornar doutor e conquistar aquele reconhecimento reservado apenas para essa classe de cidadãos, pessoas superiores em si e por si mesmas, na verdade, pensava Isaías, "era uma outra casta, para a qual eu entraria, e desde que penetrasse nela, seria de osso, sangue e carne diferente dos outros - tudo isso de uma qualidade transcendente, fora das leis gerais do universo e acima das fatalidades da vida comum". (BARRETO, 2010, p. 76)

Mas o desenrolar da história mostra as dificuldades que o jovem moço encontraria na capital, desprezado pela sua origem e pela sua cor, massacrado pelo preconceito e pela discriminação: "foram de imensa angústia esses meus primeiros dias no Rio de Janeiro. Eu era como uma árvore cuja raiz não encontra mais terra em que se apoie e donde tire vida; era como um molusco que perdeu sua concha protetora e que se vê a toda hora esmagado pela menor pressão". (BARRETO, 2010, p. 107)

Toda a vida de Isaías será marcada pela mediocridade de um homem que, lançado à sua própria sorte, não consegue romper as barreiras da ojeriza social, sem ter ao seu dispor nenhum dos remédios republicanos que pudesse alterar essa realidade. Como acentua Alfredo Bosi,

[...] o que Lima Barreto nos revela, pela boca de Isaías Caminha, é o drama da subida precocemente interrompida. Ingressando na vida adulta, o jovem promissor se vê desamparado dos primeiros apoios e cai na esfera competitiva de um meio onde vicejam a hostilidade ou o desprezo pelo pobre e, em particular, pelo negro e pelo mestiço. (In: BARRETO, 2010, p. 12)

Francisco de Assis Barbosa, por sua vez, citando as palavras do próprio Lima Barreto, acentua esse mesmo propósito da obra literária:

Que pretendeu Lima Barreto com o Isaías Caminha? Responderei com as próprias palavras do escritor, em carta que escreveu a um confrade de letras, em 1911. Pretendeu simplesmente mostrar que 'um rapaz nas condições do Isaías, com todas as disposições, pode falhar, não em virtude de suas qualidades intrínsecas, mas batido, esmagado, prensado pelo preconceito'. (BARRETO, 2010, p. 41) 
Da escrita de Lima Barreto emerge, de maneira clara, a frustração das promessas depositadas na Constituição de 1891, mais especificamente, o fracasso da implantação do ideal republicano da igualdade perante a lei, solenemente declarado no art. $72, \S 2^{\circ}$, do texto constitucional, com uma retumbante proclamação da extinção dos privilégios, prerrogativas e regalias.

Aliás, o intuito de Isaías era livrar-se de sua incômoda condição social de excluído, subumano, mas para fazer parte daquele seleto grupo de sobre-humanos, os doutores! Isaías não acreditava propriamente no projeto da república no Brasil, pois estava muito mais interessado em ser reconhecido do que se mobilizar em torno de uma causa. Lima Barreto coloca Isaías, assim, entre o sonho de alcançar o prestígio social e as humilhações cotidianas que lhe eram impostas, e com isso desvela, a seu modo, a práxis social da primeira república, com a naturalização das desigualdades.

\section{A INDISPENSABILIDADE DO ESTADO DE DIREITO E SUA INSUFICIÊNCIA}

Os romances podem estar inseridos em determinados países e épocas diversos, no entanto, são leituras capazes de dizer muito atualmente à nossa sociedade, capazes de levar o leitor a questionar valores e certezas ainda vigentes, de regras incorporadas a partir de um "senso comum teórico" - tal qual proposto por Luis Alberto Warat (WARAT, 1982) - naturalizador e formalizador do pensamento jurídico.

No texto de Ellison, muito bem organizado, muito bem escrito, o narrador, sempre incógnito, transporta-nos ao passado e, a partir daí, tece o enredo: excelente aluno, frequenta uma universidade para negros, que para ele era o melhor dos mundos possíveis, e pretende ficar na universidade como professor ou como membro do conselho administrativo. Devido a uma falta considerada muito grave, cometida no âmbito das severas regras de comportamento, foi expulso. 0 reitor entrega-lhe várias cartas de recomendação para administradores que o poderão ajudar na procura de emprego. Mas a mensagem nelas contida 
não será capaz de subverter uma realidade que se mantém ou que não se transforma, mesmo diante das conquistas ditas civilizatórias do Estado e do Direito como Estado de Direito.

Por isso, desde logo é preciso ter presente que o projeto - sempre inacabado - de Estado de Direito precisa ser compreendido nos seus exatos e próprios limites, como inserido na tradição do liberalismo como doutrina político-jurídica que não se descola de seus viéses econômico (capitalismo) e moral (liberdade), bem como de seu sujeito central - o indivíduo egoísta.

Dito de outra forma, mesmo o "novo" Estado (Liberal) Democrático de Direito, assumido formalmente pelo constitucionalismo brasileiro pós-1988, não se imuniza dos constrangimentos (im)postos por tal desenho político-moral-econômico, mantendo seus alicerces vincados na proteção do indivíduo - portanto nas liberdades, na segurança do cidadão individual etc -, no capitalismo como fundamento econômico por isso mesmo mantém-se a centralidade da propriedade privada, da economia de mercado, como fundamentos da Ordem Econômica, mesmo que matizadas pela ideia de função social.

Ou seja, o aclamado Estado (Liberal) Democrático de Direito não transforma a realidade construída historicamente, as desigualdades, as iniquidades e, muitas vezes, até mesmo as neutraliza e naturaliza, impedindo de tornar visíveis situações que, na aparência da normatividade, escondem as mazelas de uma sociedade fundada na exclusão, em particular, daquelas expressas pela questão racial, de regra intimamente conectada com a questão sócio-econômica ${ }^{1}$.

Para demonstrar tal afirmativa basta dar uma navegada nos dados históricos em torno da desigualdade econômica, da questão do trabalho escravo, dos aspectos de gênero, da violência, do encarceramento etc, como há pouco divulgado por diversos atores ${ }^{2}$.

Muito antes da proposta de 1988, em grande medida, já no início da "saga de promessas" de um Estado de Direito (liberal), no Brasil, a promessa constitucional, como se sabe, fracassou logo no início, com a reprodução das práticas herdadas do império (e da colônia), decorrentes da naturalização da desigualdade, o que forjou o surgimento dos subcidadãos brasileiros, uma gente desprovida de reconhecimento 
e que, por isso mesmo, revelou-se incapaz de assumir plenamente um sentimento constitucional, muito embora, em várias ocasiões, mesmo diante das adversidades, tenha levantado a voz contra a opressão e a marginalização.

Da escrita de Lima Barreto emerge, de maneira clara, a frustração das promessas depositadas na Constituição de 1891, mais especificamente, o fracasso da implantação do ideal republicano da igualdade perante a lei, solenemente declarado no art. $72, \S 2^{\circ}$, do texto constitucional, com uma retumbante proclamação da extinção dos privilégios, prerrogativas e regalias.

Aliás, o intuito de Isaías era livrar-se de sua incômoda condição social de excluído, subumano, mas para fazer parte daquele seleto grupo de sobre-humanos, os doutores! Isaías não acreditava propriamente no projeto da república no Brasil, pois estava muito mais interessado em ser reconhecido do que se mobilizar em torno de uma causa. Lima Barreto coloca Isaías, assim, entre o sonho de alcançar o prestígio social e as humilhações cotidianas que lhe eram impostas, e com isso desvela, a seu modo, a práxis social da primeira república, com a naturalização das desigualdades.

Tal evidencia aquilo que podemos assumir como limites próprios do Estado (Liberal) de Direito, seja como um Estado "de classes" - como muito bem demonstrado, no campo do Direito, pelos trabalhos do Prof. António José Avelãs Nunes (AVELÃS NUNES, 2013) -, seja como um Estado "territorializado", como evidenciado pelo primeiro autor deste trabalho (BOLZAN DE MORAIS, 2015).

Por evidente, deve-se considerar, aqui também, um conjunto de conquistas construídas ao longo da experimentação do Estado (Liberal) de Direito na tentativa de responder àquilo que lhe foi sendo apresentado, tais como, em um primeiro momento aquilo que podemos nomear de questão individual, após confrontada com a clássica questão social para, já no século XX, somar-se as questões ambiental e informacional, como dilemas experimentados pelas possibilidades de destruição das condições de vida do planeta Terra e da reviravolta tecnológica promovida pela nomeada Revolução da Internet ou Quarta Revolução Industrial, na passagem da era da informação para a era da quantificação (SADIN, 2015). 
Muitos são os fatores que impactam, contemporaneamente o projeto - sempre inacabado - do Estado (Liberal) de Direito, para além daqueles antes apontados, seja porque ela já não limita os poderes, sobretudo quando temos presente que poder e política estão cada vez mais distantes, sabendo-se que esta fórmula se constitui em um ambiente no qual poder e política eram, pelo menos em boa extensão, interconectados. Da mesma forma é perceptível o processo de desconstitucionalização experimentado seja pela instauração de um modelo de exceção permanente - ao estilo de G. Aganbem (2004) - e/ou à emergência de poderes selvagens - como sugerido por L. Ferrajoli (2011).

Assim percebido, o Estado (Liberal) de Direito, comprometido geneticamente à suas origens liberais, em especial pelos vieses econômico e moral, bem como impactado circunstancialmente pela perda de sua referência geográfica, incorpora também fragilidades institucionais que ultrapassam, por óbvio, sua incapacidade de funcionar como uma instância de transformação social profunda, enfrentado atores tradicionais que questionam a sua própria "legitimidade" propondo o que P. Bonavides nomeou como "golpe de Estado institucional" (BONAVIDES, 2001), a transformação das formas de afetação de garantias clássicas com a privacidade e a igualdade e a reformulação paradigmática da expressão do Direito com a reintrodução na cena pública daquilo que foi olimpicamente sonegado pela cultura jurídica tradicional - as normas técnicas, os indicadores, os standarts (FRYDMAN, 2018).

Tudo isso, nos faz retornar ao problema central deste texto: quais são as condições e possibilidades para que o Estado de Direito, elemento central do constitucionalismo moderno e contemporâneo, torne visível seus próprios limites e insuficiências para dar visibilidade a todos aqueles que vivem nos seus subterrâneos, e porque meios.

Veja-se que, como diz Luiz Maurício Azevedo:

Homem invisível é um ataque frontal a dois tipos de ilusão. A primeira é de que pessoas negras podem se comportar como pessoas brancas e obter do mundo as mesmas reações que colheriam se não fossem negras. A segunda é a de que um projeto de coletividade - seja ele político, seja ele religioso - pode oferecer resposta para as angústias profundas de um indivíduo. Ellison se esforçou para demonstrar em sua obra que fatores 
socioeconômicos turvavam a visão sobre um ser humano, mas que não podiam determiná-lo. (AZEVEDO, 2019)

Mesmo que, para este autor, tal obra possa ser (...)de certa forma inútil para o Brasil, país onde o capitalismo hiberna, há décadas, em um limbo que coaduna atraso e identidade racial esquizofrênica, pode-se tomalo emprestado para tentarmos, exatamente compreender o porque de o Estado (Liberal) Democrático de Direito, agora parte de nossa tradição constitucional, não conseguir funcionar para a quebra desta reiterada democracia racial tão, repetidamente, divulgada, mesmo que tenhamos, de há muito, uma literatura histórica e sociológica que tem evidenciado a falácia de tal assertiva.

A ausência desse "ethos mínimo" (liberal) de igualdade, de respeito à legalidade e de impessoalidade "dentro do Estado", que deveria estar presente no desenrolar do século XX, capaz de efetivamente nutrir os "outsiders" de possibilidades de inserção e participação na sociedade, parece ter inexistido no transcurso da história brasileira.

A ausência desse ethos moderno, capaz de cimentar as suas próprias práticas e instituições, constitui o pano de fundo para a explicação acerca do fenômeno da naturalização da desigualdade nas sociedades da nova periferia, como a brasileira. Aqui um detalhe importante sobre uma diferença entre as duas obras: a primeira - de Ellison - trabalhada neste texto, não enfoca estas questões institucionais "periféricas", de uma sociedade imperialismo português, como a brasileira, já a segunda - de Barreto, sugere, além das "dificuldades de cor pele" também a questão classista focada no privilégio das elites que se apoderaram do Estado brasileiro nos últimos 200 anos.

Assim como a ordem competitiva dos países centrais apresenta um discurso legitimador da desigualdade, internalizado sob o manto da legalidade e da igualdade formal, a ordem competitiva da sociedade brasileira 'também tem a 'sua hierarquia', ainda que implícita, opaca e intransparente aos atores, e é com base nela, e não em qualquer 'resíduo' de épocas passadas, que tanto negros quanto brancos, sem qualificação adequada, são desclassificados e marginalizados de forma permanente". (BOURDIEU, 2007, p. 162) 
A "esquematização" da sociedade brasileira, no campo de direito, que muito nos interessa aqui, refletida nos rumos do Estado, estava preparada para favorecer uma determinada classe dominante e, no campo jurídico, especificamente, as escolhas feitas em cada momento, entre interesses, valores, e visões do mundo diferentes ou antagonistas tinham poucas probabilidades de desfavorecer os dominantes, de tal modo o ethos dos agentes jurídicos que está na sua origem e a lógica imanente dos textos jurídicos que são invocados tanto para os justificar como para os inspirar estão adequados aos interesses, aos valores e à visão do mundo dominantes. (BOURDIEU, 2002, p. 242)

Com isso, sustentamos que a dificuldade de se erguer pilares mínimos liberais (e também sociais) de um modelo consistente de Estado de Direito gera um verdadeiro déficit de cidadania no Brasil, fruto, de um longo processo histórico de construção da subcidadania, resultante da negação de direitos aos excluídos do projeto republicano. (MOREIRA; DE PAULA, 2015)

\section{A TÍTULO DE CONCLUSÃo}

Na pesquisa materializada neste texto, buscou-se discutir, numa perspectiva histórica, a principal ferida constante da realidade social de um país periférico ou de modernidade tardia como o Brasil: a questão da naturalização da desigualdade que desemboca numa visão da subcidadania do negro como um fenômeno de massa, a qual, como apontado, não é uma exclusividade destas terras.

Essa temática, tão abordada por diversos ramos das ciências sociais, ainda não foi devidamente enfrentada pelo Direito Constitucional, talvez, justamente pela falta de empenho na construção de uma Teoria da Constituição e do Estado adequada à realidade de Estados como o Brasil.

Aqui, a naturalização da desigualdade é abordada a partir da descrição da realidade norte-americana, na obra de Ralph Elison, "Invisible Man", para se discutir a "invisibilidade do negro na sociedade", bem como, especificamente no caso brasileiro, do século XX, tal e qual retratada, metaforicamente, obra literária de Lima Barreto, em seu 
romance "Recordações do escrivão Isaías Caminha", que revelam, de maneira bem contundente, o fracasso das promessas de um Estado de Direito e republicanas depositadas na Constituição de 1891.

Esse processo de naturalização da desigualdade desemboca nos dias de hoje, evidenciando que, por meio do Direito, a capacidade transformadora sugerida pela Constituição ainda está longe de atingir a sua plenitude no que diz respeito a cura da ferida social pela transformação (do status quo) da realidade periférica brasileira, haja visto que os juristas ainda seguem atrelados ao formalismo normativista, operando, por consequência, o recalque das potencialidades transformadoras do direito e a efetivação de uma hermenêutica emancipatória, assegurando, por conseguinte, o distanciamento do saber jurídico da realidade social. Nesse diapasão, os operadores jurídicos acabam se transformando em reprodutores de fórmulas antigas e mantenedores de um sistema social que avilta as condições de vida da grande massa oprimida e o direito passa a ser a ferramenta deste mecanismo.

A partir do Estado Democrático de Direito sugerido pelo texto constitucional, a cidadania no Brasil deve ser reestruturada, principalmente à luz dos ideais transformadores desse modelo de Estado, que sugerem, principalmente, a melhoria das condições sociais no Brasil. Para tanto, a Carta assume uma postura compromissária dirigente, com metas bem definidas, principalmente a favor daqueles que sempre se viram alijados de qualquer possibilidade de participação materialmente democrática no Estado e na sociedade.

Mas para que tudo isso aconteça, é necessário que a máquina estatal efetivamente direcione os seus mais eficazes mecanismos de atuação para o âmbito social e deixe de privilegiar o dirigismo financeiro voltado para os interesses do mercado e da economia privada ${ }^{3}$ em detrimento de um necessário dirigismo social.

É necessário que se combata este sincretismo teórico e político contrário à Constituição Dirigente, ou seja, é preciso que se resista às teorias e práticas que, por um lado atacam “(...) os dispositivos constitucionais relativos às políticas públicas e direitos sociais", sob o pretexto que esses “'engessam' a política retirando a liberdade de atuação do legislador”, e, por outro, defendem as “(...) políticas de estabilização 
e de supremacia do orçamento monetário sobre as despesas sociais". (BERCOVICI; MASSONETO, 2006, p. 72)

Por isso, é preciso ter presente que o projeto de Estado de Direito, continua e continuará como um belo e necessário projeto enquanto não conseguir promover efetivamente um mínimo de resposta à esta realidade histórica que não deixa de ser um presente histórico, lançando mão dos instrumentos necessários seja para a repressão às condutas contrárias, seja para a implementação de políticas públicas aptas a recompor esta dívida histórica e civilizacional.

\section{NOTAS}

1 No Brasil é assente e baseada em dados insuspeitos a "continuidade" entre pobreza, exclusão e raça, além, é claro, de gênero e/ou opções sexuais, bastando uma verificada nos dados ligados à população carcerária que, para além de ser a terceira maior do mundo, é majoritariamente composta por pessoas pobres e negras ou pardas, para o que aqui importa.

2 Exemplificativamente: 8 pessoas mais ricas tem uma riqueza igual metade mais pobre da população; 815 milhões passam fome; Conflitos no Séc. XX mataram 3x mais que o resto da história; Trabalho infantil: 152 milhões; Escravidão moderna: 40 milhões; População carcerária BR: 711.463; 6 mais ricos $=100$ milhões de brasileiros.

3 Dessa forma, na chamada crise do financiamento do setor público, “(...) o orçamento público deve estar voltado para a garantia do investimento privado, para a garantia do capital privado, em detrimento dos direitos sociais e serviços públicos voltados para a população mais desfavorecida. Assim, nesta etapa, o direito financeiro na organização do espaço político-econômico da acumulação, passa a servir a uma nova função do Estado - a tutela jurídica da renda do capital e da sanção de ganhos financeiros privados, a partir da alocação de garantias estatais ao processo sistêmico de acumulação liderado pelo capital financeiro". Portanto, a "(...) implementação da ordem econômica e da ordem social da Constituição de 1988 ficaram restritas, assim, às sobras orçamentárias e financeiras do Estado". (BERCOVICI; MASSONETO, 2006, p. 69 e 71). 


\section{REFERÊNCIAS}

AGAMBEN, Giorgio. Estado de exceção. São Paulo: Boitempo. 2004.

AVELÃS NUNES, António José. O Estado capitalista e suas máscaras. 3. ed. Lisboa: Ed. Avante. 2013.

AZEVEDO, Luiz Maurício. Ralph Elisson: a causa e o efeito. https://revistacult. uol.com.br/home/ralph-ellison-a-causa-e-o-efeito/. Publicado em 16/04/2019. Acesso em 20 de novembro de 2019.

BARBOSA, Francisco de Assis. A vida de Lima Barreto. 9. ed. Rio de Janeiro: José Olympio, 2003.

BARRETO, Lima. Recordações do escrivão Isaías Caminha. 2. ed. São Paulo: Penguin Classics Companhia das Letras, 2010.

BERCOVICI, Gilberto; MASSONETO, Luís Fernando. A Constituição Dirigente Invertida: A Blindagem da Constituição Financeira e a Agonia da Constituição Econômica. In Boletim de Ciências Econômicas da Faculdade de Direito da Universidade de Coimbra. Coimbra (Portugal), vol. XLIX, 2006.

BOLZAN DE MORAIS, Jose Luis. O Estado e Constituição e o fim da geografia. In: STRECK, Lenio Luiz; ROCHA, Leonel Severo; ENGELMANN, Wilson. Constituição, Sistemas Sociais e Hermenêutica. Anuário do Programa de Pós-Graduação em Direito da UNISINOS. Porto Alegre: Livraria do Advogado. 2015. p. 69-82

BONAVIDES, Paulo. Do país constitucional ao país neocolonial. São Paulo: Malheiros. 2001.

BOURDIEU, Pierre. 0 Poder Simbólico. Traduzido por Fernando Tomaz. 5. ed. Rio de Janeiro: Bertrand Brasil, 2002.

BOURDIEU, Pierre. Distinção: crítica social do julgamento. Traduzido por Daniela Kern; Guilherme J. F. Teixeira. São Paulo: Edusp; Porto Alegre: Zouk, 2007.

ELLISON, Ralph. Homem invisível. Trad. Márcia Serra. São Paulo: Marco zero, 1990. 
FERRAJOLI, Luigi. Poteri Selvaggi. La crisi dela democrazia italiana. Roma-Bari: Laterza. 2011.

FRYDMAN, Benoit. 0 Fim do Estado de Direito. Governar por standards e indicadores. 2 ${ }^{\mathrm{a}}$ ed. Coleção Estado e Constituição. № 17. Porto Alegre: Livraria do Advogado. 2018.

MOREIRA, Nelson Camatta; De Paula, Rodrigo. Lima Barreto: subcidadania, negação do Estado de Direito e Constitucionalismo Dirigente no Brasil. In: MOREIRA, Nelson Camatta Moreira; OLIVEIRA, Juliana Ferrari de. Direito \& Literatura e os múltiplos horizontes de compreensão pela arte. Unijuí-RS: Editora Unijuí, 2015.

RIBEIRO, Renato Janine. Democracia versus república: a questão do desejo nas lutas sociais. Disponível em: <http://www.renatojanine.pro.br/FiloPol/versus. html>. Acesso em 17.08.2012.

SADIN, Éric. L'humanité augmentée. L'adminitration numérique du monde. Paris: Échappée. 2013.

SADIN, Éric. La Vie Algorithmique. Critique de la raison numérique. Paris: Échappée. 2015.

SADIN, Éric. L'intelligence artificielle ou l'enjeu du siècle. Anatomie d'um antihumanisme radical. Paris: Échappée. 2018.

WARAT, Luis Alberto. Saber crítico e senso comum teórico dos juristas. Revista Sequência. Vol. 03. № 5. 1982, p. 48-57. https://periodicos.ufsc.br/index.php/ sequencia/article/view/17121/15692. Acesso em: 5 nov. 2019.

Recebido em: 17/12/2019

Aprovado em: 17-12-2019

Autores convidados 


\section{Jose Luis Bolzan de Morais}

Doutor em Direito do Estado (UFSC, com doutoramento sandwich na Université de Montpellier I - France). Estágios de pós-doutoramento na Universidade de Lecce-IT (2004) e Coimbra-PT (2007 - bolsista CAPES/GRICES) Pesquisador PQ/CNPQ. Professor do PPGD/FDV. Professor convidado Università di Firenze (2017/2018). Líder do Grupo de Pesquisa CNPQ “Estado \& Constituição (GEPE\&C) Membro da Rede Internacional de Grupos de Pesquisa CNPq Estado e Constituição (REPE\&C). Procurador do Estado do Rio Grande do Sul junto aos Tribunais Superiores - Brasília/DF. E-mail: bolzan@hotmail.com

\section{Nelson Camatta Moreira}

Doutor em Direito (UNISINOS-RS), com estágio de pesquisa anual na Universidade de Coimbra - bolsa CAPES. Pós-doutoramento em Direito (Universidad de Sevilla) - bolsa CAPES. Pós-doutoramento em Direito (Universidade do Vale do Rio dos Sinos: UNISINOS-RS). Líder do Grupo de Pesquisa FDV-ES/CNPq "Teoria Crítica do Constitucionalismo", da FDV-ES. Professor da Programa de Pós-graduação Stricto Sensu (Doutorado e Mestrado) e da Graduação em Direito da FDV-ES. Membro da Rede Internacional de Grupos de Pesquisa CNPq Estado e Constituição (REPE\&C). Presidente da Rede Brasileira Direito e Literatura. E-mail: nelsoncmoreira@hotmail.com

Faculdade de Direito de Vitória. Programa de Pós-Graduação em Direitos e Garantias Fundamentais

Rua Juiz Alexandre Martins de Castro Filho, 215. Santa Lúcia. Vitória - ES. CEP 29056-295 